\title{
Maintanence Treatment in Opioid Dependency
}

Yeşim Can, Elif Mutlu, Vahap Karabulut, Arzu Çiftçi Demirci, Gökhan Umut, Turan Çetin

Psychiatrist, Bakırköy Prof. Dr. Mazhar Osman Training and Research Hospital for Psychiatry, Neurology and Neurosurgery, AMATEM Clinic, Istanbul - Turkey

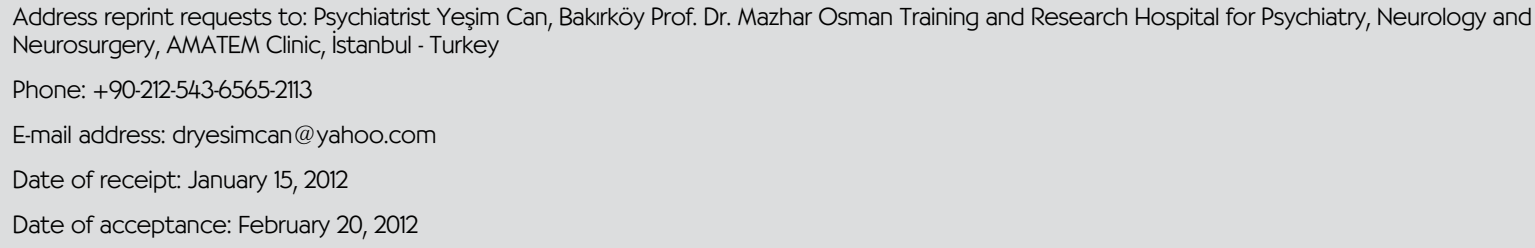

Dear Editor,

It has been 1.5 year since Suboxone ${ }^{\circledR}$ is approved for the use in opioid dependence in Turkey. It comprises the partial mu-opioid receptor agonist buprenorphine in combination with the opioid antagonist naloxone in a $4: 1$ ratio. When buprenorphine/naloxone is taken sublingually as prescribed, naloxone exerts no clinically significant effect, leaving the opioid agonist effects of buprenorphine to predominate. However, when buprenorphine/naloxone is parenterally administered in patients physically dependent on full agonist opioids, the opioid antagonism of naloxone causes withdrawal effects, thus reducing the abuse potential of the drug combination. Buprenorphine/naloxone is an effective maintenance therapy for opioid dependence and has generally similar efficacy to full agonist methadone (1).

Clinical guidelines and clinical audit to enhance compliance with guidelines are helpful in maintaining the quality and integrity of the opioid treatment system, and can contribute to keeping diversion within acceptable levels (2). Also the results of the recent study showed significant interregional differences of opioid addicts which might require different treatment strategies in European countries to handle the problem (3). With this perspective, we who are working in Alcohol Drug Dependence Treatment Research and
Training Center (AMATEM) have written a guideline for the use of Suboxone ${ }^{\circledR}$ (4), since up until now it only can be prescriped in AMATEM clinics.

During this process, we asked 7 questions to 2 professionals who have been treating opioid dependents in different parts of Europe. James Bell is currently working in London (National Addiction Centre, Institute of Psychiatry, King's College London, London, UK), whereas Rudolf Stohler is working in Zurich (Psychiatric University Hospital, Zurich, Switzerland). We wanted to share these answers with the readers of your journal.

Question 1. Which factors should be considered to determine the treatment strategy, maintenance vs. withdrawal therapy with Suboxone ${ }^{\circledR}$ ?

James Bell - Patients need to be informed of the high risk of relapse, and the risk of overdose, after completing detoxification and be advised that longer term treatment (maintenance) is more likely to producing lasting benefit. If despite this advice the patient is strongly motivated to withdraw, that is the appropriate course - with warnings as to the potential risks associated with relapse.

Rudolf Stohler - I think that this decision should be made by the patient, if she or he is legally competent to do so. When a professional advice is wanted, I'd suggest the following: The longer the patient is 
dependent on heroin (or other opioids), the more likely she/he will profit from substitution treatment and vice versa. Furthermore, I think inpatient withdrawal treatment in closed wards is a dangerous undertaking.

Question 2. What do you think about the patients receiving substitute and abstinence oriented treatment taken along in the same therapentic community/ or inpatient clinic? Do you think the goals and the conditions of therapy should be diverse between these groups?

James Bell - I personally think that trying to maintain a divide between abstinence-oriented and maintenance-oriented services is counterproductive, and detracts from the priorities of treatment - reducing risk, interrupting chaotic drug use, building sustainable recovery. All people presenting for treatment of opioid dependence are ambivalent, motivation is fluctuating, and I think its better to acknowledge that there are differing paths to recovery and that people have choices.

Rudolf Stohler - Basically, I think this is feasible and - mostly due to economic pressure - we had to learn how to do it in Switzerland.

Question 3. When should we discontinue the substitution therapy? Do you think it should be indefinite?

James Bell - Substitution treatment can be indefinite, but most patients want to come off (and many do so prematurely). People have the best chance of coming off when they have ceased injecting and/or misusing drugs, and have built a sustainable recovery things like employment, stable relationship and stable mental health.

Rudolf Stohler - This decision should be made together with the each patient separately. I think patients should not be excluded against their will, e.g. because of consumption of street drugs.

Question 4. Is abiding psychotherapy necessary in patients receiving substitution or a couple of sessions of psychoeducation may be sufficient?

James Bell - Psychotherapy is not required. What is required is a therapeutic relationship, in which patients are monitored and reviewed (as one monitors patients with diabetes, hypertension, or depression).
Rudolf Stohler - In my eyes, it is better to only provide substitution medication than nothing. See also articles by Schwartz et al. (5) However, best would be to provide long-term support for (re-)integration, ideally by the same person.

Question 5. What do you recommend for patients who are not oriented to the substitution programmes or who are extricated from the programme scores of times?

James Bell - Many people respond poorly, and sometimes when people are very chaotic it is necessary to stop their treatment. Generally, if they restart and stop repeatedly, it might be useful to suggest a different approach to treatment, such as a residential rehabilitation.

Rudolf Stohler - Our experience is that almost all of those who have become dependent from heroin enter substitution treatment, if it is provided without too many restrictions (low threshold substitution).

Question 6. Do you think the patients receiving substituonal therapy should keep a driving license? What are your opinions regarding risky employments such as to be armed, driving, work as a police officer, etc?

James Bell - People stable in treatment should not be prevented from holding a driving license. During induction, people should be warned against driving. People abusing benzodiazepines or alcohol should not have a driver license. I do not think people on OST should work in safety-sensitive occupations (such as airline pilots, bus drivers). In relation to possession of firearms, or working in the police force, the critical question is whether they have a criminal record which would preclude these things.

Rudolf Stohler- I think that patients, who are stable in a stable substitution treatment can do almost everything.

Question 7. How do you see the abuse/diversion potential of Suboxone?

James Bell - Suboxone ${ }^{\circledR}$ can be diverted, for sublingual or intravenous misuse, and can be injected by heroin users when they are in withdrawal. It is probably slightly reinforcing when injected, and in a proportion of opioid-dependent patients will produce a 
moderate precipitated withdrawal. As such, it is less susceptible to diversion. But there is still a place for other measures to reduce diversion, including supervised administration for people who are not stable

\section{REFERENCES}

1. World Health Organization. Department of Mental Health and Substance Abuse. Guidelines for the psychosocially assisted pharmacological treatment of opioid dependence. 2009.

2. Bell J. The global diversion of pharmaceutical drugs: opiate treatment and the diversion of pharmaceutical opiates: a clinician's perspective. Addiction 2011; 106:1656-1657.

3. Reissner V, Kokkevi A, Schifano F, Room R, Storbjörk J, Stohler R, Difuria L, Rehm J, Geyer M, Hölscher F, Scherbaum N. Differences in drug consumption, comorbidity and health service use of opioid addicts across six European urban regions (TREATproject). Eur Psychiatry 2011 (In press). in treatment (6).

Rudolf Stohler - I think it's slightly less than that of Subutex ${ }^{\circledR}$ or methadone. But there is still little experience and we should wait and see.

4. Evren C, Can Y, Mutlu E, Karabulut V, Çiftci-Demirci A, Umut G, Çetin T. Suboxone (buprenorfin: nalokson) uygulama kılavuzu. Bakırköy Prof. Dr. Mazhar Osman Ruh Sağlığı ve Sinir Hastalıkları Eğitim ve Araştırma Hastanesi, AMATEM Kliniği, Şubat 2012

5. Schwartz RP, Kelly SM, O'Grady KE, Gandhi D, Jaffe JH. Randomized trial of standard methadone treatment compared to initiating methadone without counseling: 12-month findings. Addiction 2011 (In press).

6. Mammen K, Bell J. The clinical efficacy and abuse potential of combination buprenorphine-naloxone in the treatment of opioid dependence. Expert Opin Pharmacother 2009; 10:2537-2544. 